\title{
Smear-layer Removal Using Two Instrumentation and Irrigation Techniques in a Closed System
}

\author{
Sadullah Kaya \\ ${ }^{1}$ Associate Professor, Dicle University, Faculty of Dentistry, Department of Endodontics, Diyarbakır, TURKEY
}

\section{Key Words}

Continuous irrigation, manual irrigation, Self-adjusting file, ProTaper, smear layer

\section{Correspondence:}

Sadullah KAYA

Dicle University,

Faculty of Dentistry,

Department of Endodontics,

21280, Diyarbakir, TURKEY.

e-mail: sadullahkaya@hotmail.com

\section{Abstract}

\begin{abstract}
Aim: The aim of this study was to evaluate the effectiveness of two instrumentation and irrigant techniques in smear-layer removal from root canals.

Methodology: Thirty single-rooted teeth were randomly divided into two groups. Group 1 (continuous irrigation) was prepared using Selfadjusting file, and group 2 (manual irrigation; conventional needle irrigation) was prepared using with ProTaper file system. Groups were irrigated using sodium hypochlorite (5\%) as an initial irrigant following MTAD in a closed system. Canals were bisected and examined by scanning electron microscopy. Smear layers were evaluated using a five-point scoring system with 2500x magnification.
\end{abstract}

Results: Smear layers were eliminated in the coronal, middle, and apical thirds of the root canal, respectively, in $93 \%, 80 \%$, and $60 \%$ of samples in the group 1 , and $67 \%, 60 \%$, and $27 \%$ in the group 2 , of the coronal, middle, and apical thirds of the root canals, respectively. Evaluation by SEM showed continuous irrigation differed not-significantly from the manual irrigation group in all areas $(P>0.05)$.

Conclusions: Smear layer can be removed properly with suitable irrigation methods.

(Int Dent Res 2012;2(3):60-66)

\section{Introduction}

The irrigation of the root-canal system is important in endodontic treatment (1). As Yamada et al (2) stated, endodontic irrigants are delivered to the root-canal areas during treatment to help dissolve organic tissues and to remove loose debris and the smear layer. The smear layer is a significant factor affecting endodontic instrumentation. This thin, amorphous structure covers prepared root canal walls and occludes the orifices of dentinal tubules (3). The smear layer contains inorganic and organic substances $(3,4)$. Rigorous removal of necrotic remnants of pulp tissue, microorganisms, and microbial toxins from the root canal system is necessary for endodontic success (5). This smear layer, which contains bacterial cells, impedes proper canal filling and prevents the diffusion of dentin canals by bacteria (6).

Instruments alone are not capable of producing a clean canal wall. Irrigation plays a key role in successful debris and removing smear layer during root canal preparation (7). The debridement efficacy of an irrigation system depends on several factors, such as the ability to deliver the irrigant to the apical and noninstrumented regions of the canal space. It is also important to create sufficient turbulence to 
move debris away from the canal walls during debridement $(8,9)$. Because the root is enclosed by the alveolum during in vivo cleaning and shaping (10), the canal imitates a closed-end channel. This results in gas entrainment (11), producing a vaporlock effect during irrigation (12). Studies designed to simulate a closed-canal system by embedding roots in a polyvinyl siloxane impression material have reported insufficient debridement from the apical canal walls with the use of a syringe-delivery technique (13). In conventional needle irrigation, the effectiveness of irrigant replenishment and exchange in the apical third of the root canal are dependent on the depth of penetration (14). Chemomechanical instrumentation contributes to the success of root canal therapy. $\mathrm{Ni}-\mathrm{Ti}$ rotary instruments have recently become popular because they are safe when used according to the manufacturers' instructions, can rapidly enlarge root canals, and are well suited to the shaping of even severely curved canals $(15,16)$. The shaping ability of root canal instruments is determined by a complex interrelationship of parameters, such as cross-sectional design, smear- and debris-removal capacity, and instrument surface treatments (16). ProTaper instruments are characterized by multiple and progressive taper combined with negative rake angle (17). The SAF is a new file system in the form of a thin-walled, hollow, compressible, pointed cylinder with a Ni-Ti cage. Its diameter is 1.5 or 2 $\mathrm{mm}$ and its thickness is $120 \mu \mathrm{m}$. A file with a 1.5$\mathrm{mm}$ diameter fits readily into a canal that has been prepared with a size- $20 \mathrm{~K}$-file, and a file with a 2$\mathrm{mm}$ diameter fits into a canal that has been prepared with a size-30 K-file (18). Both K-files were designed for single use $(18,19)$. The SAF adapts three-dimensionally throughout the canal and is operated with an in-and-out manual movement. An irrigation device manufactured for use with the SAF (VATEA; ReDent-Nova) can transmit 1-10 mL/min continuous solution from the hollow file system to the root canal. This irrigation contacted the dentin walls, thereby removing a uniform 60-75- $\mu$ m-thick dentin layer (19). In this system, 2-min irrigation cycles were performed using a silicone tube (inner diameter $1.587 \mathrm{~mm}$, outer diameter $3.175 \mathrm{~mm}$; Degania Silicone, Ltd., Degania, Israel) for a total of $4 \mathrm{~min}$ at 3,000-5,000 rpm (19). The scanning electron microscope (SEM) has proved to be a valuable method in the comparison of smear layer on root canal wall after preparation with different canal instruments (20).

The present study was designed to evaluate the effectiveness of two irrigation techniques on intracanal smear-layer removal using two instrumentation techniques in a closed system.

\section{Materials and Methods}

Thirty human maxillary and mandibular incisors with single roots and straight root canals that had been extracted within the previous 2 months for reasons unrelated to the present study were collected and stored in $10 \%$ buffered formalin until they were used. After accessing the endodontic cavity, the root canal was negotiated using a size 10-K file (Lexicon; Tulsa Dental Products, Tulsa, OK). The working length was set $1 \mathrm{~mm}$ shorter than the apical foramen. A glide path was established by manual instrumentation up to a size $20-\mathrm{K}$ file using 5 $\% \mathrm{NaOCl}$. The teeth were randomly divided into two groups. Teeth in Group 1 (continuous irrigation, $\mathrm{n}=$ 15) were prepared with an SAF (SAF; ReDent-Nova, Ra'anana, Israel) (Fig 1), and in Group 2 (manual irrigation, $\mathrm{n}=15$ ) with a ProTaper file (DentsplyMaillefer, Ballaigues, Switzerland). The MTAD irrigation agent were preferred for use with the continuous irrigation system and manual irrigation system.

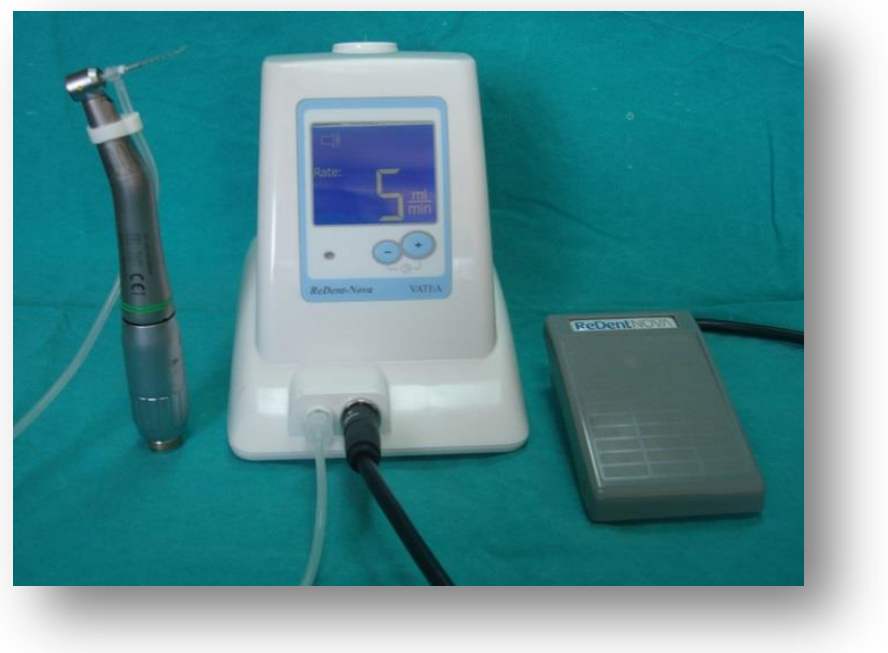

Figure 1. The SAF file with its irrigation device.

\section{The closed system}

To generate a closed system, the apical foramen of each root was coated with hot, flexible glue gel (Loctite $₫$ Super Glue; ULTRA Gel Control ${ }^{\mathrm{TM}}$, Westlake, $\mathrm{OH}$; Fig. 2A). After the gel hardened, each root was embedded in a plexiglass tube filled with a clear polyvinyl siloxane impression material (Imprint $^{\mathrm{TM}}$ II; 3M, St. Paul, MN), as suggested previously (21) (Fig. 2B). The closed system (Fig. 2C) prevented irrigant extrusion from the apical foramen during canal preparation and irrigation. 


\section{For continous irrigation;}

A glide path was established by manual instrumentation up to a size $20-\mathrm{K}$ file using $5 \%$ $\mathrm{NaOCl}$. The root canals were then prepared using an SAF file (ReDent-Nova) with an in-and-out vibrating handpiece, as described by Metzger et al (18). The SAF file was used in two cycles of 2 min each (total, $4 \mathrm{~min}$ ). $5 \% \mathrm{NaOCl}$ (total, $10 \mathrm{~mL}$ ) was used as the irrigant during the first cycle, and MTAD (Dentsply/Tulsa, Tulsa, OK, USA) (total, $10 \mathrm{~mL}$ ) during the second cycle. The irrigation agents entered the canal through the file, permeated the canal freely, and flowed out of the canal's entrance cavity. All teeth were washed with $10 \mathrm{~mL}$ distilled water to remove any remaining MTAD and dried with paper points.

\section{For manual irrigation;}

\section{Syringe Irrigation with Needle}

During preparation, the canals were irrigated with $5 \% \mathrm{NaOCl}$ and MTAD using a 30-gauge irrigation needles (conventional needle irrigation group) according to the following procedures:

The teeth in Group 2, each root was instrumented to size $\mathrm{F} 3$ with a crowndown approach and irrigated with $5 \% \mathrm{NaOCl}$ (in total volume of 10 $\mathrm{mL}$, for $2 \mathrm{~min}$ ) at each file change. After $10 \mathrm{~mL}$ of MTAD irrigation agent was applied for $2 \mathrm{~min}$, the teeth were washed with $10 \mathrm{~mL}$ distilled water and dried with paper points.

\section{SEM Evaluation and Image Analysis}

The crowns were removed. Two longitudinal grooves were prepared on the buccal and lingual surfaces of each root using a diamond disc, avoiding penetration into the canal. The roots were then split into 2 halves with a chisel and coded. The coded specimens were mounted on metallic stubs, gold sputtered, and examined independently by three observers (who were not otherwise involved in the study) using SEM (JEOL T330; JSM, Tokyo, Japan) after the examination of 15 specimens for calibration purposes.

After general evaluation of the canal wall, of all teeth SEM photomicrographs were taken at magnifications of $2500 \mathrm{X}$ at the coronal $(10 \mathrm{~mm}$ to apex), middle (6 $\mathrm{mm}$ to apex), and apical ( $2 \mathrm{~mm}$ to apex) thirds of each specimen for the smear layer.

The cleaning abilities of the group 1, and group 2 were evaluated using the smear-layer scoring systems introduced by Hülsmann et al (22). The researchers collaborated in examination of the specimens and comparison of the scores.

The smear layer was evaluated on images taken at $2500 \times$ magnification using the following five scores (22). A score of 1 indicated that the smear layer was absent and all dentinal tubules were open, 2 indicated a small smear layer and openness of some dentinal tubules, 3 indicated a homogeneous smear layer covering the root canal wall, and only a few open dentinal tubules, 4 indicated complete coverage of the root canal wall with a homogeneous smear layer, and no open dentinal tubules, and a score of 5 indicated a heavy homogeneous smear layer that completely covered the root canal wall. This scoring system was applied to the coronal, middle, and apical thirds of the root canals. All results were then grouped into "clean canal wall" (scores 1 and 2) or "smear layer present" (scores 3-5).
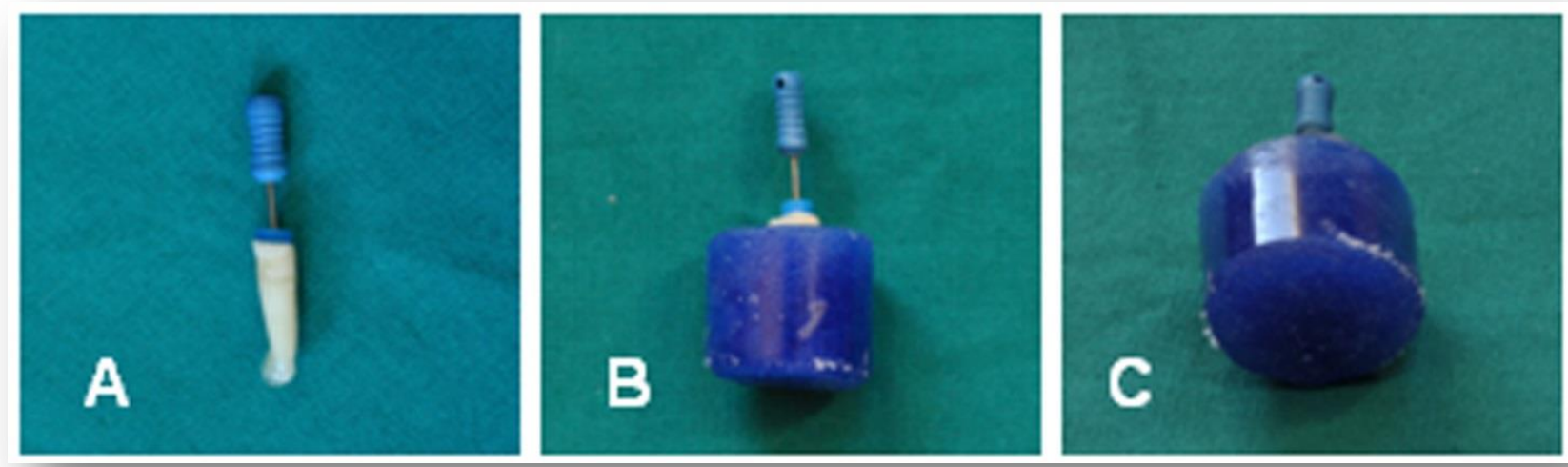

Figure 2. (A) The apical foramen was covered with flexible glue gel for the closed system; (B) Roots were immersed into a polyvinyl siloxane impression material; (C) The bottom of the system was kept closed. 


\section{Results}

\section{Smear layer}

Table 1 presents the smear layer scoring results for all groups. 14 of 15 (93\%) and 12 of 15 (80\%) teeth in the group 1 had scores indicating clean canal walls (scores 1 and 2 ) in the coronal and middle thirds of the root canals, respectively (Fig. $3)$.
1 of $15(7 \%)$ samples in this group had scores of 3-5 in the coronal third of the canal, and 3 of 15 (20\%) had scores of 3-5 in the middle third of the canal. 9 of $15(60 \%)$ apical thirds had scores of 1 or 2 , and 6 of $15(40 \%)$ had scores of 3-5.

10 of $15(67 \%)$ coronal thirds, 9 of $15(60 \%)$ middle thirds, and 4 of $15(27 \%)$ apical thirds in the group 2 had scores of 1 or 2 (Fig. 3). 5 of 15 (33\%) coronal thirds, 6 of $15(40 \%)$ middle thirds, and 11 of $15(73 \%)$ apical thirds of root canals in this group had scores of 3-5.

\section{Group 1}
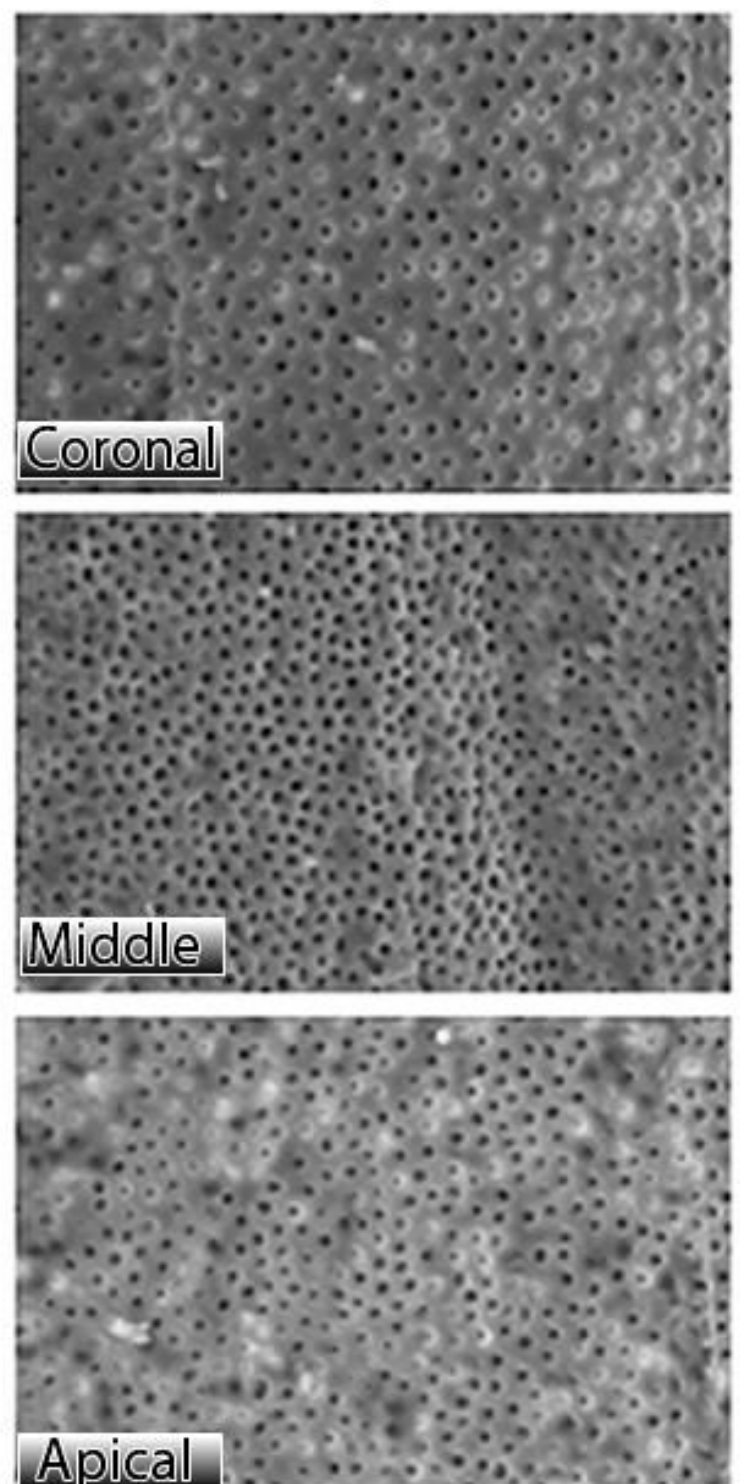

Group 2
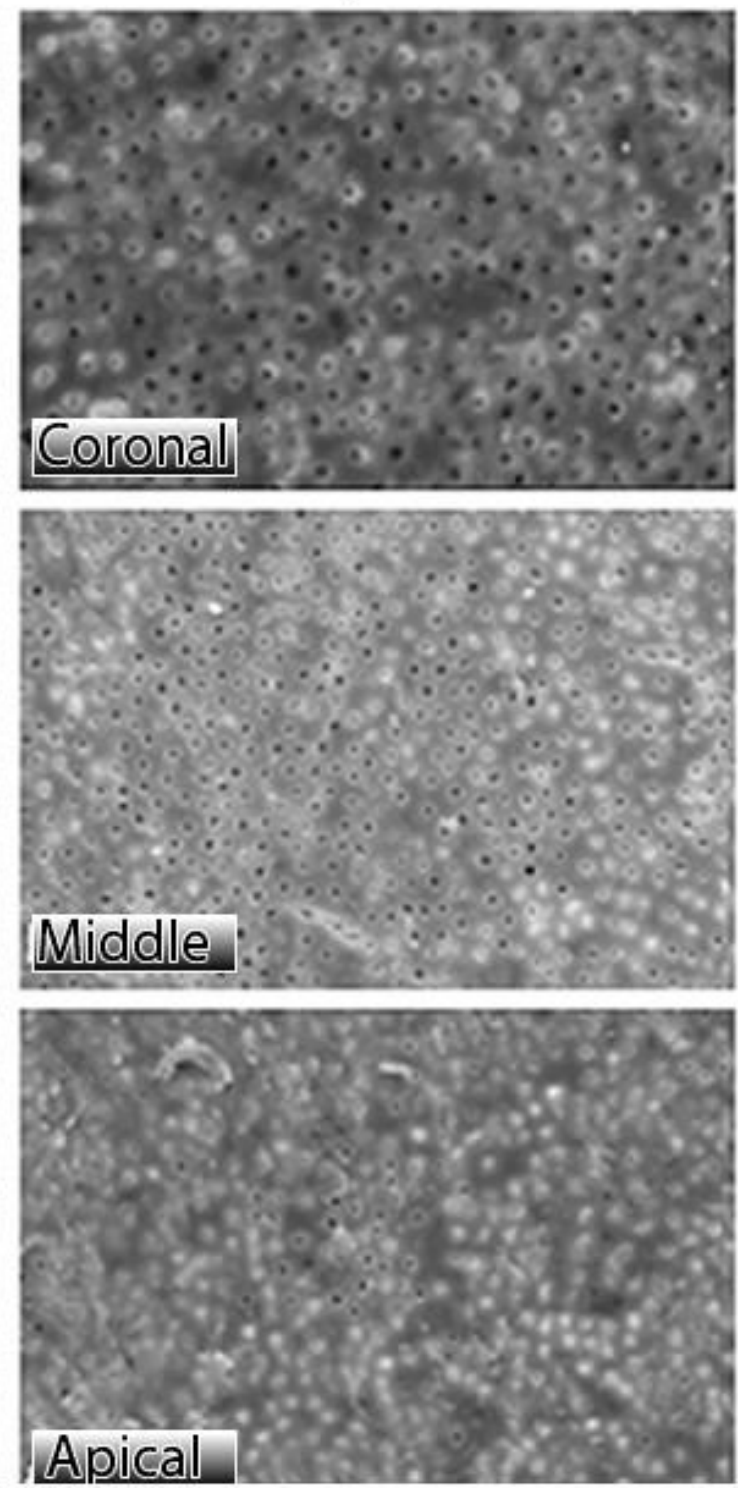

Figure 3. (Group 1) The smear-layer-free surface of a root canal after treatment with continuous irrigation. The coronal, middle, and apical thirds of the canal received a score of 1 , using the smear-layer scoring system of Hülsmann et al22 Original magnification: 2500X; (Group 2) Scanning electron microscopic (SEM) image of a root canal in the manual irrigation group. The coronal and middle thirds received scores of 2, and the apical third received a score of 3. Original magnification: 2500X. 
TABLE 1. The percentages of smear layer removal scores of root canals.

\begin{tabular}{|c|c|c|c|c|c|c|c|c|c|c|c|c|}
\hline \multirow[t]{3}{*}{ Groups } & \multicolumn{4}{|c|}{ Coronal region } & \multicolumn{4}{|c|}{ Middle region } & \multicolumn{4}{|c|}{ Apical region } \\
\hline & \multicolumn{4}{|c|}{ Ilean Smear layer present } & \multicolumn{4}{|c|}{ Smear layer present } & \multicolumn{4}{|c|}{ Clean Smear layer present } \\
\hline & $1^{a}$ & 3 & 4 & 5 & 1 & 3 & 4 & 5 & 1 & 3 & 4 & 5 \\
\hline Group 1 & $\begin{array}{c}7 / 15^{b} 7 / 15 \\
14 / 15 \\
(93 \%)^{c} \\
\end{array}$ & $1 / 15$ & $\begin{array}{c}0 \\
1 / 15 \\
(7 \%) \\
\end{array}$ & 0 & $\begin{array}{cc}6 / 15 \quad 6 / 15 \\
12 / 15 \\
(80 \%) \\
\end{array}$ & $2 / 15$ & $\begin{array}{l}1 / 15 \\
3 / 15 \\
(20 \%) \\
\end{array}$ & 0 & $\begin{array}{c}4 / 15 \quad 5 / 15 \\
9 / 15 \\
(60 \%) \\
\end{array}$ & $4 / 15$ & $\begin{array}{l}2 / 15 \\
6 / 15 \\
(40 \%) \\
\end{array}$ & 0 \\
\hline Gruop 2 & $\begin{array}{c}5 / 15 \quad 5 / 15 \\
10 / 15 \\
(67 \%) \\
\end{array}$ & $4 / 15$ & $\begin{array}{l}1 / 1 \\
5 / 1 \\
(33 \% \\
\end{array}$ & 0 & $\begin{array}{c}3 / 15 \quad 6 / 15 \\
9 / 15 \\
(60 \%) \\
\end{array}$ & $4 / 15$ & $\begin{array}{r}2 / 15 \\
6 / 15 \\
(40 \%) \\
\end{array}$ & 0 & $\begin{array}{l}0 \quad 4 / 15 \\
4 / 15 \\
(27 \%) \\
\end{array}$ & $4 / 15$ & $\begin{array}{l}7 / 15 \\
11 / 15 \\
(73 \%) \\
\end{array}$ & 0 \\
\hline
\end{tabular}

\footnotetext{
${ }^{\mathrm{a}}$ Smear layer scores (Hülsmann et $\mathrm{al}^{22}$ ).

${ }^{\mathrm{b}}$ Number of canals presenting with a given score.

'Dichotomized scores: scores 1 to 2 (clean canal wall) versus 3 to 5 (smear layer present).
}

\section{Statistical Analysis}

Statistical analysis was performed using SPSS (Version 15.0; Chicago, USA). Fisher's Chi-square test was used for comparisons between groups.

The data were evaluated statistically with a significance set at .05. Fisher's Exact Chi-Square test found not-significant differences in the scores of the coronal, middle, and apical areas in each of the two groups $(P>0.05)$.

\section{Discussion}

The success of endodontic treatment is affected by the operator's choice of endodontic files, rotary instrumentation, irrigation techniques, chelating agents, and evaluation methods (23). Because the root is enclosed by the alveolum during in vivo preparation (10), the canal imitates a closedend channel. This results in gas entrainment (11), producing a vapor-lock effect during irrigation (12). Tay et al (21) reported a difference in the smear layers of closed and open root-canal systems and found that the apical vapor lock adversely affected debridement efficacy. They suggested that studies failing to specify the mechanism by which fluid flow through the apical foramen was limited must be evaluated with caution (21). According to this suggestion, a closed system was generated in the present study.

To achieve optimal efficiency, irrigants must be brought into direct contact with the entire root-canal wall (23). To improve root-canal cleanliness, it is necessary to increase the flushing action (24). The effectiveness of irrigation solutions may be improved by the use of different agitation techniques, including agitation with plastic instruments, hand files, and sonic and ultrasonic devices (25). Most studies of irrigation efficiency have been conducted on straight root canals. The improvement of irrigation techniques is necessary in the apical region of root canals $(24,26)$. The recent development of nickel titanium ( $\mathrm{Ni}-\mathrm{Ti}$ ) rotary files with advanced blade designs has improved cleaning efficacy during root canal preparation (27).

Canal instruments must facilitate the shaping of root canals in a manner that allows clearing with irrigation solutions, disinfection with medicaments, and, ultimately, obturation. The apical size of a preparation is also a factor in the effective cleaning of root canals (28). The SAF system developed by Metzger et al (19) provides the necessary depth and flexibility for three-dimensional adaptability during root canal shaping, and allows continuous irrigation throughout the canal through the vibratory activation of irrigation materials. During active rotary instrumentation, continuous irrigant agitation increases the volume, contact time, and depth of irrigant penetration inside the root canal (19). This should result in more effective canal debridement than that achieved using needle irrigation (25). Before the advent of passive ultrasonic activation, traditional syringe irrigation was defended as an effective method of irrigant delivery. This technique is widely accepted by general practitioners and endodontists (29). An irrigant is dispensed into a root canal through needles of variable gauges, either passively or with agitation. This technique allows the irrigant to flow backward and increases the coronal displacement of debris while avoiding the inadvertent expression of irrigant into periapical tissues. Syringe irrigation facilitates the control of needle penetration depth within the root canal and the volume of irrigant that is flushed through the canal (29). After conventional needle irrigation, unattainable canal extensions and irregularities may protect debris and bacteria; incomplete canal debridement may thus be destructive (30). A previous study has shown that conventional needle 
irrigation delivered irrigating solution only $1 \mathrm{~mm}$ deeper than the tip of the needle (31). Removal of the smear layer and debris is more readily accomplished in the cervical and middle thirds of root canals than in the less-accessible apical third $(19,32,33,34)$. Effective irrigation of the canal is essential in the critical the apical area during rootcanal treatment. Continuous irrigation can effectively remove the smear layer in the apical part of the root canal (19). In addition to continuous irrigant replacement, this factor may explain the superior cleaning efficiency observed in the present study. The results of the present study revealed differences in smear-layer removal between continuous and manual irrigation in the coronal, middle, and apical thirds of the canals. Specifically, manual irrigation produced higher smear-layer scores in the apical region. This may be due to the penetration of irrigants into the apical third of the root canals. In an assessment of the continuous irrigation system, Metzger et al (19) found that smear layers were absent (scores 1 or 2 ) in $100 \%$ of coronal thirds, $80 \%$ of middle thirds, and $65 \%$ of apical thirds in their root canal sample. Yiğit Özer et al (35) reported $64 \%$ of the root canal wall with smear layer scores 1 and 2 for the apical thirds of curved root canals in maxillary molar teeth. In the current study, smear layers were successfully removed in $93 \%, 80 \%$, and $60 \%$ (coronal, middle, apical thirds) of root canals in the continuous irrigation group, and $67 \%, 60 \%$, and $27 \%$ in the manual irrigation group, respectively. Although continuous irrigation system removal smear layer better than manuel irrigation system, there isn't any statisticaly significant difference between groups $(P>0.05)$. Successful removal of the smear layer for continuous irrigation gruop through the entire root may be due to the vibrating motion of the SAF within the continuously replaced fluid.

\section{Conclusion}

Smear layer can be removed properly with suitable irrigation methods. Previous studies will be done about comparation of continuous irrigation system with other irrigation system.

\section{Acknowledgments}

This work was supported by Research Fund of the Dicle University. Project Number: 09-DH-28

\section{References}

1. Bystrom A, Sundqvist G. Bacteriologic evaluation of the efficacy of mechanical root canal instrumentation in endodontic therapy. Scand J Dent Res 1981;89:321-28.

2. Yamada R, Aramas A, Goldman M, Lin PS. A scanning electron microscope comparison of a high volume final flush with several irrigating solutions. Part 3. J Endod 1983;9:137-42.

3. Mader $\mathrm{CL}$, Baumgartner JC, Peters DD. Scanning electron microscopic investigation of the smeared layer on root canal walls. J Endod 1984;1:47783.

4. Kaya S, Ganidağlı Ayaz S, Uysal İ, Akkuş Z. Comparison of the Impact of LongTermApplications of MTAD and EDTA Irrigation Agents on Dentin Structure: A Scanning Electron Microscope Study. Int Dent Res 2011;1(2):60-4.

5. Sjogren $U$, Hagglund $B$, Sundqvist $G$, et al. Factors affecting the long-term results of endodontic treatment. J Endod 1990;16:498504.

6. Torabinejad $M$, Handysides $R$, Khademi AA, Bakland LK. Clinical implications of the smear layer in endodontics: a review. Oral Surg Oral Med Oral Pathol Oral Radiol Endod 2002;94:65866.

7. Shoji $S$, Hariu $H$, Horiuchi $H$. Canal enlargement by Er:YAG laser using a cone-shaped irradiation tip. J Endod 2000;26:454-8.

8. Boutsioukis C, Lambrianidis T, Kastrinakis E. Irrigant flow within a prepared root canal using various flow rates: a computational fluid dynamics study. Int Endod J 2009;42:144-55.

9. Gao $Y$, Haapasalo $M$, Shen $Y$, et al. Development and validation of a three-dimensional computational fluid dynamics model of root canal irrigation. J Endod 2009;35:1282-7.

10. Burleson A, Nusstein J, Reader A, Beck M. The in vivo evaluation of hand/rotary/ ultrasound instrumentation in necrotic, human mandibular molars. J Endod 2007;33:782-7.

11. Pesse AV, Warrier GR, Dhir VK. An experimental study of the gas entrapment process in closedend microchannels. Int J Heat Mass Transfer 2005;48:5150-65.

12. de Gregorio C, Estevez R, Cisneros R, Heilborn C, Cohenca N. Effect of EDTA, sonic, and ultrasonic activation on the penetration of sodium hypochlorite into simulated lateral canals: an in vitro study. J Endod 2009;35:891-5.

13. Albrecht L, Baumgartner JC, Marshall JG. Evaluation of apical debris removal using various sizes and tapers of ProFile GT files. J Endod 2004;30:425-8.

14. Siu C, Baumgartner JC. Comparison of the Debridement Efficacy of the EndoVac Irrigation System and Conventional Needle Root Canal Irrigation In Vivo. J Endod 2010;36:1782-5.

15. Schäfer E, Erler M, Dammaschke T. Comparative study on the shaping ability and cleaning efficiency of rotary Mtwo instruments. Part 2. Cleaning effectiveness and shaping ability in 
severely curved root canals of extracted teeth. Int Endod J 2006;39:203-12.

16. Hülsmann $M$, Peters $O$, Dummer $P M H$. Mechanical preparation of root canals. Shaping goals, techniques and means. Endod Topics 2005;10:30-76.

17. Schäfer $E$, Vlassis $M$. Comparative investigation of two rotary nickel-titanium instruments: ProTaper versus RaCe. Part 1. Shaping ability in simulated curved canals. Int Endod J 2004; 37:229-38.

18. Metzger Z, Teperovich E, Zary R, Cohen R, Hof R. The self-adjusting file (SAF): part 1-respecting the root canal anatomy: a new concept of endodontic files and its implementation. J Endod 2010;36:679-90.

19. Metzger Z, Teperovich E, Cohen R, Zary R, Paque' $F$, Hülsmann M. The Self-adjusting File (SAF). Part 3: Removal of Debris and Smear Layer-A Scanning Electron Microscope Study. J Endod 2010;36:697-702.

20. Jeon IS, Spångberg LS, Yoon TC, Kazemi RB, Kum KY. Smear layer production by 3 rotary reamers with different cutting blade designs in straight root canals: a scanning electron microscopic study. Oral Surg Oral Med Oral Pathol Oral Radiol Endod 2003;96:601-7

21. Tay FR, Gu L-S, Schoeffel GJ et al. Effect of vapor lock on root canal debridement by using a side-vented needle for positive-pressure irrigant delivery. J Endod 2010;36:745-50.

22. Hülsmann M, Rümmelin C, Schäfers F. Root canal cleanliness after preparation with different endodontic handpieces and hand instruments: a comparative SEM investigation. J Endod 1997;23:301-6.

23. Zehnder $M$. Root canal irrigants. J Endod 2006;32:389-98.

24. Gutarts R, Nusstein J, Reader A, Beck M. In vivo debridement efficacy of ultrasonic irrigation following hand-rotary instrumentation in human mandibular molars. J Endod 2005;31:166-70.

25. Gu LS, Kim JR, Ling J, Choi KK, Pashley DH, Tay FR. Review of contemporary irrigant agitation techniques and devices. J Endod 2009;35:791804.

26. Kuah HG, Lui JN, Tseng PS, Chen NN. The effect of EDTA with and without ultrasonics on removal of the smear layer. J Endod 2009;35:393-6.

27. Adıgüzel Ö. A Literature Review of Self Adjusting File. Int Dent Res 2011;1:18-25.

28. Card SJ, Sigurdsson S, Orstavik D, Trope M. The effectiveness of increased apical enlargement in reducing intracanal bacteria. J Endod 2002;28:779-83.

29. van der Sluis LW, Gambarini G, Wu MK, Wesselink PR. The influence of volume, type of irrigant and flushing method on removing artificially placed dentine debris from the apical root canal during passive ultrasonic irrigation. Int Endod J 2006;39: 472-6.

30. Wu MK, Wesselink PR. A primary observation on the preparation and obturation of oval canals. Int Endod J 2001;34:137-41.
31. Ram Z. Effectiveness of root canal irrigation. Oral Surg Oral Med Oral Pathol Oral Radiol Endod 1977; 44:306-12.

32. Paqué $F$, Musch $U$, Hülsmann M. Comparison of root canal preparation using RaCe and ProTaper rotary $\mathrm{Ni}-\mathrm{Ti}$ instruments. Int Endod J 2005;38:816.

33. Adıgüzel Ö, Yiğit Özer $S$, Kaya $S$, Uysal İ, Ganidağlı Ayaz S, Z Akkuş. Effectiveness of EDTA and MTAD on debris and smear layer removal using a Self-adjusting file, Oral Surg Oral Med Oral Pathol Oral Radiol Endod,2011;112(6):7905.

34. Kaya S, Adıgüzel Ö, Uysal İ, Ganidağlı Ayaz S, Akkuş Z. Effectiveness of three different application times of $17 \%$ EDTA and $7 \%$ Maleic Acid irrigation agents on the removal of debris and the smear layer: A Scanning Electron Microscope Study. Int Dent Res 2011;1(2):48-54.

35. Yiğit Özer S, Adıgüzel Ö, Kaya S. Removal of debris and smear layer in curved root canals using self-adjusting file with different operation times - a scanning electron microscope study. Int Dent Res 2011;1:1-6. 